\title{
"Diets and heart disease. Myths and reality"
}

\author{
Annamaria Martino ${ }^{1,3}$, Emilia Goanta ${ }^{1}$, Roberta Magnano ${ }^{2}$, Sabrina Bencivenga ${ }^{2}$, Laura Pezzi ${ }^{2}$, Angelo \\ Acitelli $^{2}$, Adelaide Piccarozzi ${ }^{1}$, Maria Penco ${ }^{2}$, Leonardo Calo ${ }^{1 *}$ \\ ${ }^{1}$ Division of Cardiology, PoliclinicoCasilino, Via Casilina, Rome, Italy \\ ${ }^{2}$ Department of Cardiology, University of l'Aquila, Via Giovanni di Vincenzo, Italy \\ ${ }^{3}$ Cardiovascular, Respiratory, Nephrologic and Geriatrics Sciences Department, Umberto I Hospital, Rome, Italy
}

Received: May 01, 2016; Accepted: May 26, 2016; Published: June 12, 2016

*Corresponding author: Leonardo Calo, MD, FESC. Division of Cardiology, Policlinico Casilino, Via Casilina 1049, 00169, Rome, Italy, Tel: 00390623188416; Fax: N 00390623188410; E-mail: leonardo.calo@tin.it

\begin{abstract}
Cardiovascular diseases are the leading cause of death in the developed countries. The crucial role of diet and lifestyle in the prevention of cardiovascular disease is well known.

Aim: The purpose of this review is to investigate the real impact of food, antioxidant agents, nutraceuticals, coffee and tea on cardiovascular diseases.

Methods: We critically reviewed papers focusing on relationship between food consumption, antioxidant agents, nutraceuticals, coffee and tea and risk of cardiovascular disease incidence and mortality.

Results: Mediterranean diet proved to reduce the risk of cardiovascular diseases. Numerous studies have demonstrated the efficacy of nutraceutical in reducing total and LDL cholesterol and triglyceride levels in dyslipidemic subjects. In the large majority of studies, moderate coffee drinking proved to be not detrimental to cardiac health, but even beneficial. Finally, some studies suggested that green tea might protect against the development of coronary heart disease.

Conclusion: A healthy diet, rich in antioxidant agents, and administration of nutraceuticals, help prevent cardiovascular diseases.
\end{abstract}

\section{Introduction}

About 2400 years ago, Hippocrates said: "Let your food be your medicine and your medicine be your food". The importance of food in order to cure and prevent disease was well known to the ancient Indian, Egyptian and Chinese civilization that have used natural herbs and spices as traditional medicine for centuries. Initially, research in the field of food was limited to its aroma and energy value, but later moved towards the identification of components with pharmacological properties to be used in the prevention and treatment of cardiovascular diseases, diabetes and of dyslipidemia.

The aim of this paper is to summarize and critically review, evidence regarding the Mediterranean diet, antioxidant properties of food, caffeina, nutraceuticals and cardiovascular prevention.

\section{Methods}

This review presents mechanisms potentially involved in the influence of food, coffee, tea, and nutraceuticals in Cardiovascular Diseases (CVD) and dyslipidemias and critically evaluates the most important observational and clinical evidence available. A comprehensive search of published reports with Pub Med was done on the topics of: "Mediterranean Diet and CVD", "Antioxidant agents and CVD", "Caffeina, teina, and CVD", "Nutraceuticals and CVD". Criteria for consideration were papers written in English that linked each of the topics indicated above to CVD and that illustrated mechanisms involved in their modulation.

\section{Results}

\section{Epidemiology of cardiovascular disease}

CVD remains the leading cause of death among Europe and around the world. It has been estimated that $29.6 \%$ of all deaths in 2010 worldwide were caused by CVD, with a prevalence two times superior to that of cancers and much more higher than all maternal, neonatal and nutritional disorders combined together [1]. In Europe, CVD causes more than 4.3 million deaths per year and costs at least $€ 190$ billion [2]. The burden still remains high, and varies dramatically between countries, with a high rate mortality in East Europe. Coronary heart disease, when considered separately, accounts for almost 1.8 million deaths annually (20\% of all deaths in Europe). Finally, of all deaths that occur before the age of 75 years in Europe, $42 \%$ are due to CVD in women and $38 \%$ in men [3].

The World Health Organization has stated that over threequarters of all CVD deaths may be prevented by adopting changes in lifestyle behaviour. Moreover, the American Heart Association and the European Society of Cardiology have defined that people who tend to stay healthy are those having no smoking habitude, adequate physical activity, healthy eating habits, no overweight, normal values of blood pressure, cholesterol and fasting glucose, 
and avoidance of excessive stress [3].

Results from clinical trials and natural experiments have also shown that a decline in CVD mortality can happen rapidly after individual or population-wide changes in diet or smoking [4]. Therefore, one can conclude that a healthy lifestyle is the cornerstone of primary prevention, and may allow achieving better results than any drug therapy.

\section{Dyslipidemias}

Dyslipidemias are a group of metabolic abnormalities characterized by an alteration in the amount of lipids in the blood, caused either by an inherited genetic disorder or by a diet too rich in fats [5]. Cholesterol is mostly produced by the liver and partially introduced with food. Once absorbed in the intestine, cholesterol is transported by lipoproteins to the liver, where it flows into bile acids. Lipid metabolism can be disturbed at various levels, including:

1. Low-density lipoprotein (LDL) receptor (90\% of cases), with consequent reduction in binding to LDL-cholesterol (LDL-C).

2. Apo B (5\% of cases), with consequent incorrect binding of LDL-C to its receptor

3. Proprotein Convertase Subtilisin/Kexin Type 9 (PCSK9) ( $1 \%$ of cases), with consequent increased degradation of the intracellular LDL receptor and lower recycling of LDL-C on the cell surface;

4. Low Density Lipoprotein Receptor Adaptor Protein 1 (LDLRAP1), with consequent impaired endocytosis of LDL-R/ LDL complex.

Elevation of Total Cholesterol (TC) and LDL-C has been associated with CVD [6]. Moreover, a $1.0 \mathrm{mmol} / \mathrm{L}(\sim 40 \mathrm{mg} / \mathrm{dL})$ LDL-C lowering has proved to cause a proportional reduction in all-cause mortality, cardiac death, major coronary events and stroke of $10 \%, 20 \%, 23 \%$ and $17 \%$ respectively, in various subgroups of patients [6].

International guidelines [7] suggest that all men over 40 and women over 50 years should have a lipid screening including TC, LDL-C, High-Density Lipoprotein-Cholesterol (HDL-C) and triglycerides. Moreover, guidelines suggest LDL-C as the primary target of therapy in most strategies of dyslipidemia management, with a therapeutic target $<70 \mathrm{mg} / \mathrm{dl}$ in very high-risk individuals [7].

Nutritional strategies to improve dyslipidemias are primarily based on physical activity and weight loss, that exert a modest role in achieving low LDL-C levels, but can improve HDL-C levels and triglycerides. Moreover, changing some 'risky' dietary components and encouraging the consumption of 'healthy' functional foods and/or dietary supplements including phytosterols, soy protein, N-3 Unsaturated Fatty Acids (N-3 PUFA) is essential.

Statins are the more efficacious drug in reducing LDL-C. Several kind of statins with different clinical efficacy are available. The choice of one type or the other is made in relation to the therapeutic goal in each individual patient and to the effectiveness and tolerability of the molecule. Further therapeutic approaches to the management of hypercholesterolemia are:

- Bile acid sequestrants

- Cholesterol absorption inhibitors (such as ezetimibe)

- Nicotinic acid

- LDL apheresis, that remove LDL and Lipoprotein A from plasma during extracorporeal circulation and is reserved to patients with severe hyperlipidaemias

- Lomitapide, that inhibit the microsomal triglyceride transfer protein, which is necessary for very low-density lipoprotein (VLDL) assembly and secretion in the liver.

- Alirocumab and Evolocumab [8], that are human recombinant antibodies, known as PCSK9 inhibitors. PCSK9 is a protein that targets LDL receptors for degradation and thereby reduces the liver's ability to remove LDL-C from the blood. Evolocumab and Alirocumab bind to PCSK9 and inhibit PCSK9 from binding to LDL receptors on the liver surface.

\section{Diet and cardiovascular prevention}

Mediterranean Diet: The Mediterranean dietary model is based on a high intake of vegetables, cereals and fruit, a moderate intake of fish and a low intake of refined products, as red meat and sweets (Figure 1). Several studies have investigated the influence of the Mediterranean diet on cardiovascular diseases. A study proved that Mediterranean diet has significant inverse associations with metabolic syndrome and LDL-C levels, and is associated with high HDL-C [9]. Adherence to the Mediterranean diet also promotes weight loss, significantly reduces levels of glycated hemoglobin and represents a protective factor for coronary atherosclerosis [10].

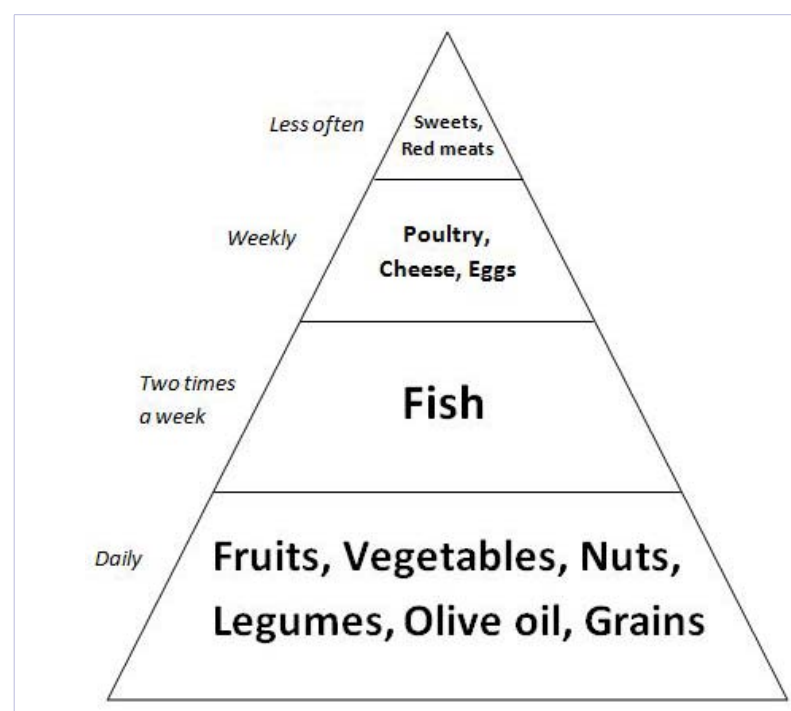

Figure 1: The Mediterranen Diet pyramid. The pyramid shows food to be consumed with different frequencies 
Several studies showed that the Mediterranean diet is inversely associated with CVD and mortality from coronary diseases and stroke [11]. Mediterranean diet, moreover, supplemented with extra-virgin olive oil or nuts, resulted in a relative risk reduction of approximately $30 \%$, among high-risk persons who were initially free of CVD [12].

DASH Diet: The DASH diet (Dietary Approaches to Stop Hypertension) is characterized by a particularly high intake of fruits and vegetables and a low intake of animal proteins, which are replaced with vegetable proteins. The DASH diet has proved to prevent and to reduce blood pressure, as well as to reduce weight, body mass index, liver enzymes, triglycerides and inflammatory markers [13]. The DASH diet has also proved to cause a reduction in stroke and CVD, and thanks to the antioxidant properties of fruits and vegetables, it seems to be helpful in chronic and degenerative diseases [14]

\section{Antioxidants and cardiovascular disease}

Reactive Oxygen Species (ROS) such as superoxide, hydroxyl radical and non-radical derivatives, are terminal products of several physiological and biochemical processes, including mitochondrial respiration and chemical reactions [15]. In recent years, considerable research has been conducted on the critical role of ROS in the pathogenesis of vascular diseases, including hypertension, atherosclerosis, diabetes mellitus, and heart failure [15].

Antioxidants are substances that "neutralize" ROS before they are able to react with cellular components and alter their structure or function. They prevent ROS accumulation by increasing intracellular scavenging or promoting their degradation [15]. When ROS generation exceeds the capacity of antioxidant defense, progressive endothelial dysfunction and apoptosis occur [16]. Increased production of ROS favours vascular dysfunction, alters micro vascular vasodilatory capacity, and favours the expression of adhesion molecules mediating the recruitment of inflammatory cells [16].

Over the years, many studies have explored the role of antioxidants in CVD and have proved that vitamin or mineral supplements are not a substitute for a balanced, nutritious diet that limits excess calories, saturated fat, trans fat, sodium, and dietary cholesterol.

A meta-analysis [17] of the largest studies of antioxidants on the effect on CVD, proved that. Vitamin E did not cause any benefit in lowering mortality compared to control treatments, and it did not significantly decrease the risk of CVD death or stroke. The lack of any beneficial effect was seen consistently regardless of the doses of vitamins used and the diversity of the patient populations. Beta-carotene led to small but statistically significant increase in all-cause mortality and a slight increase in cardiovascular death. In February 2014, also the U.S. Preventive Services Task Force [18] issued a report stating that there is not enough evidence to show that multivitamins or mineral supplements can lower the odds of getting heart disease and that vitamin E and Beta-carotene supplements have not been shown to have benefits against heart disease.
Even though supplements did not prove beneficial in avoiding heart problems, foods that are sources of antioxidants are still recommended [18]. A high intake of fruits and vegetables, dark green vegetables in particular, has been associated with a reduced risk of coronary heart disease, and total cardiovascular morbidity or mortality [19].

\section{Nutraceuticals}

The term nutraceutical is a neologism created by the fusion of the words "nutrition" and "pharmaceutical", to indicate "a food with positive effects on health, including the prevention and treatment of diseases"[20]

A distinction should be made between:

a) Nutraceuticals, that are natural extracts with medical properties;

b) Functional foods, that are foods naturally rich in, or artificially enriched with, natural substances with pharmacological properties;

c) Food supplements, which are nutrients to be added to the normal diet in case of deficiency states or increased need [20].

Nutraceuticals include various substances, among whom, the main ones are: PUFA, phytosterols, polyphenols, red yeast rice, berberine, folic acid and flavonoids (Figure 2).

PUFA: According to biochemical structure, dietary PUFA can be divided into n- 6 PUFA and n-3 PUFA. Linoleic acid is the principal n-6 PUFA; it is contained in vegetable oils and can't be synthesized by humans. It reduces LDL-C and triglycerides, increases HDL-C and improves the TC/ HDL-C ratio, thus reducing the risk of CVD [21]. N-3 PUFA includes alpha-linolenic acid, EicosaPentaenoic Acid (EPA) and DocosaHexaenoic Acid (DHA). Alpha-linoleic acid,that is contained in flaxseed, canola, walnuts, soybeans, has been demonstrated to influence platelet, endothelial function, inflammation and arterial compliance

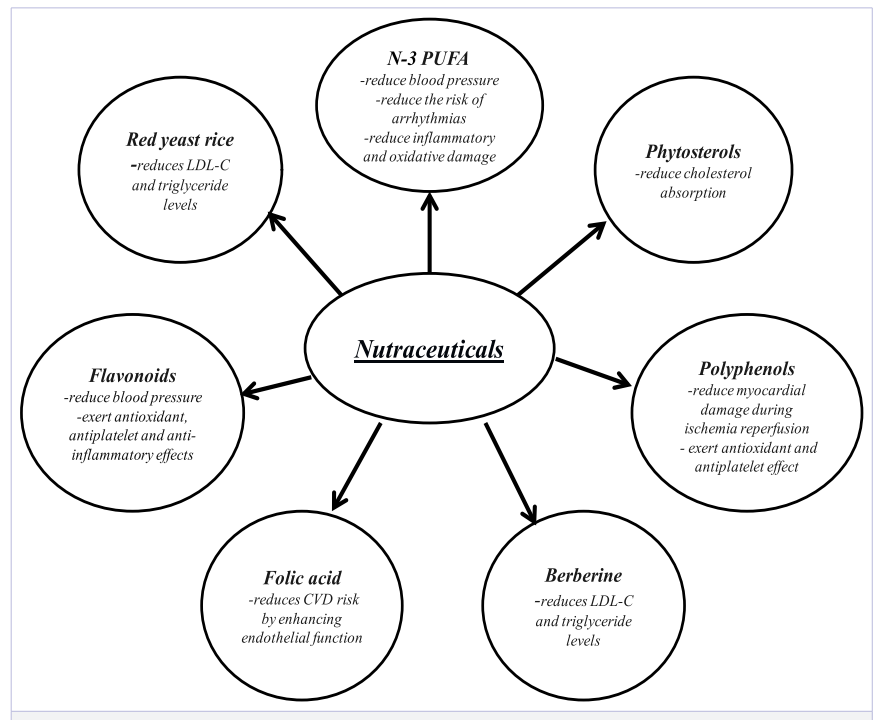

Figure 2: Nutraceuticals: cardiovascular effects. 
positively [21]. EPA and DHA acid derive from fish and shellfish Numerous studies have shown positive effects of N-3 PUFA on heart rate, blood pressure, levels of triglycerides, inflammatory response and endothelial function, and have proved their direct and indirect antiarrhythmic effects [22]. Some large studies have proved a protective effect of N-3 PUFA against fatal arrhythmic events after myocardial ischemia (Table 1) [23-26]. The effect of fish oil on Atrial fibrillation (AF), both in primary (Table 2) [27-32] and in secondary prevention (Table 3) [33-37] and after cardiac surgery (Table 4) [38-41] are controversial, mostly due to lack of homogeneity between studies [42].
Phytosterols: Phytosterols are sterols present in vegetable plants that play a role similar to cholesterol in humans. When they are included in the diet, phytosterols are able to inhibit the incorporation of cholesterol in the intestinal micelles, through a competitive mechanism, and cause a reduction of $30-40 \%$ of the absorption of dietary cholesterol, in the absence of side effects. The maximal effect of phytosterols (approximately $7 \%$ reduction in cholesterol) has proved to be achieved at a dose of 0.7-1.1 g / day [43].

Polyphenols: Hydroxytyrosol and its derivatives are natural polyphenols present in olive oil, able to reduce significantly the

Table 1: Large clinical trials on n-3 PUFA in coronary heart disease.

\begin{tabular}{|c|c|c|c|c|c|c|}
\hline Study & Study population & Treatment dose & Control & Follow-up & Primary endpoint & $\operatorname{RR}^{1}\left(95 \% \mathrm{CI}^{2}\right)$ \\
\hline GISSI-P & $\begin{array}{l}11323 \text { patients with } \\
\text { recent ( } \geq 3 \text { months) } \mathrm{MI}^{3}\end{array}$ & $\begin{array}{l}\text { EPA and DHA (ratio 1:2) } \\
850-882 \mathrm{mg}\end{array}$ & $\begin{array}{l}\text { Vitamine E vs } \\
\text { not }\end{array}$ & 3.5 years & $\begin{array}{l}\text { Death, non-fatal MI and } \\
\text { non-fatal stroke. }\end{array}$ & $0.85(0.74-0.98)$ \\
\hline JELIS & 18645 patients with & EPA $^{4} 1800 \mathrm{mg}$ plus statin & Statin alone & Mean: 4.6 years & Major coronary events & $0.81(0.69-0.95)$ \\
\hline OMEGA & $\begin{array}{l}3851 \text { patients with } \\
\text { recent ( } 3-15 \text { days) MI }\end{array}$ & $\begin{array}{l}\text { N-3 PUFA } 1 \text { g (EPA } 460 \\
\left.m g+\text { DHA }^{5} 380 \mathrm{mg}\right)\end{array}$ & Olive oil $1 \mathrm{~g}$ & 1 year & Sudden cardiac death & $0.95(0.56-1.60)$ \\
\hline $\begin{array}{l}\text { ALPHA } \\
\text { OMEGA }\end{array}$ & $\begin{array}{l}4837 \text { patients with } \\
\text { previous MI }\end{array}$ & $\begin{array}{l}\text { EPA-DHA } 400 \mathrm{mg} / \text { day } \\
\text { And EPA-DHA + } \mathrm{ALA}^{6} 2 \mathrm{~g} / \\
\text { day }\end{array}$ & $\begin{array}{l}\text { ALA 2g/day + } \\
\text { placebo }\end{array}$ & $\begin{array}{l}\text { Median: } 40.8 \\
\text { months }\end{array}$ & $\begin{array}{l}\text { Major cardiovascular } \\
\text { events }\end{array}$ & $1.01(0.85-1.17)$ \\
\hline
\end{tabular}

1 RR: Relative Risk; 2 CI: Confidence Interval; 3 MI: Myocardial Infarction; 4 EPA: Eicosapentaenoic Acid; 5 DHA: Docosahexaenoic Acid; 6 ALA: Alpha-Linoleic Acid

Table 2: Most important studies on N-3 PUFA administration in primary prevention for AF.

\begin{tabular}{|c|c|c|c|}
\hline Study design & Population & $\begin{array}{l}\text { PUFA } \\
\text { Administration }\end{array}$ & Results \\
\hline Prospective cohort & 4815 individuals; USA & $\begin{array}{l}\text { Broiled/backed fish assessment. } \\
\mathrm{FU}^{3}: 12 \mathrm{y}\end{array}$ & $\begin{array}{l}\text { Lower } \mathrm{AF}^{5} \text { risk of } 31 \% \text { with fish intake } \geq 5 \\
\text { times/week. }\end{array}$ \\
\hline Prospective cohort & 2174 subjects; Finland & $\begin{array}{l}\text { Serum } \mathrm{EPA}^{7} \text { and } \mathrm{DHA}^{8} \text { and dosage. } \\
\text { FU: } 17.7 \mathrm{y}\end{array}$ & Lower AF risk of $38 \%$ for higher DHA levels. \\
\hline Prospective cohort & 3326 subjects; USA & Serum EPA, DHA dosage & $\begin{array}{l}\text { Lower AF risk for top vs lowest quartile of } \\
\text { PUFA levels }\end{array}$ \\
\hline Prospective cohort & 47949 subjects; Denmark & Fish-oil intake assessment. FU: $5.7 \mathrm{y}$. & Higher AF risk with higher fish intake. \\
\hline Prospective cohort & 5184 subjects; the Netherland & Fish-oil intake assessment. FU: $6.4 \mathrm{y}$. & No AF risk reduction with high fish intake. \\
\hline Post-hoc analysis of a RCT & 5835 systolic heart failure-subjects & N-3 PUFAs vs placebo; FU 3.9 y & No AF risk reduction with n-3 PUFA \\
\hline
\end{tabular}

Table 3: Most important studies of N-3 PUFA administration on secondary prevention for AF.

\begin{tabular}{|c|c|c|c|}
\hline Study design & Population & PUFA administration & Results \\
\hline Double blind-RCT ${ }^{1}$ & $\begin{array}{l}109 \text { pts }^{2} \text {, } \\
\text { heart structural abnormality: } 90 \%\end{array}$ & $\begin{array}{l}\text { N-3 PUFA } 2 \text { g/day, } 1 \text { month before } \\
\text { and } 12 \text { after } \mathrm{ECV}^{3} \mathrm{vs}^{4} \text { olive oil }\end{array}$ & Less AF relapses with PUFA \\
\hline Open-label randomized & 178 pts & $\begin{array}{l}\text { N-3 PUFA } 1.8 \mathrm{~g} / \text { day for } \approx 56 \text { days before } \\
\text { and } 1 \text { year after ECV vs not. }\end{array}$ & $\begin{array}{l}\text { Less AF relapses at } 90 \text { days and } 1 \text { y } \\
\text { with PUFA; higher serum PUFA }\end{array}$ \\
\hline Double blind-RCT & 586 pts with persistent AF & N-3 PUFA $1 \mathrm{~g} /$ day for 1 year vs placebo & No lower AF with PUFA. \\
\hline Double blind RCT & 337 pts, paroxysmal or persistent AF & Fish oil ( 4 g/day) or placebo & No lower AF with PUFA. \\
\hline Double blind-RCT & 190 pts, paroxysmal or persistent AF & N-3 PUFAs or placebo & $\begin{array}{l}\text { No reduction of } \mathrm{AF}, \text { inflammation } \\
\text { markers and oxidative stress }\end{array}$ \\
\hline
\end{tabular}




\begin{tabular}{|c|c|c|c|}
\hline Study design & Population & PUFA Administration & Results \\
\hline Randomized, open label & $160 \mathrm{CABG}^{1}$ pts $^{2}$; Italy & $\begin{array}{l}\text { N-3 PUFA } \geq 5 \text { days before surgery, until } \\
\text { discharge } \text { vs }^{3} \text { not. }\end{array}$ & Lower AF risk. $P=0.013$ \\
\hline Prospective cohort & 125 CABG pts Iceland. & N3-PUFA 7 days pre-CABG vs placebo & $\begin{array}{l}\text { Positive DHA/POAF association } \\
\text { (U-curve relationship). }\end{array}$ \\
\hline Double blind-RCT ${ }^{4}$ & $\begin{array}{l}1516 \mathrm{CS}^{5} \mathrm{pts} \text {; Italy-USA- } \\
\text { Argentina. }\end{array}$ & $\begin{array}{l}\text { N3-PUFA } 5 \text { days pre-CS up to discharge } \\
\text { vs placebo }\end{array}$ & $\begin{array}{l}\text { No lower AF despite } 40 \% \text { higher } \\
\text { plasmatic PUFA }\end{array}$ \\
\hline Double blind-RCT & 243 CS pts; USA. & N-3 PUFA vs corn oil & $\begin{array}{l}\text { No lower AF despite plasma PUFA } \\
\text { increase }\end{array}$ \\
\hline Double blind RCT & 108 CABG pts; UK & N-3 PUFA for 16 days vs olive oil & $\begin{array}{l}\text { No lower AF risk despite higher serum } \\
\text { and atrial PUFA }\end{array}$ \\
\hline
\end{tabular}

amount of circulating oxidized LDL and cholesterol, thereby reducing risk of cardiovascular events. Resveratrol, that is contained in grapes and in red wine (at a concentration of 1.92 to $12.6 \mathrm{mg} / \mathrm{L}$ ), has strong antioxidant properties, modulates vascular cell function, inhibits LDL oxidation, suppresses platelet aggregation and reduces myocardial damage during ischemiareperfusion [44]. Notably, since the daily dose of resveratrol required to obtain protective cardiovascular effects is very high (3-6 g), large doses of red wine should be taken, with a series of alcohol-related negative effects. Tablet formulations of 200-400 mg are available, with proven beneficial effects [44].

Red yeast rice: Monacolin $\mathrm{K}$, also known as lovastatin, is a metabolite of the fungus Monascus purpureus and is able to inhibit HMG-CoA reductase, the key enzyme in endogenous cholesterol synthesis, thus acting as a statin [45]. Numerous studies and clinical trials have demonstrated the efficacy of red yeast rice in reducing TC, LDL-C and triglyceride levels in dyslipidemic subjects, without changes in liver function, creatinine and muscle enzymes. The recommended dose of Monacolin K for primary prevention of cardiovascular events in the general population is $10 \mathrm{mg} /$ day [45]. Notably, red yeast rice has also showed good results in secondary cardiovascular prevention, by improving lipoprotein levels and reducing new cardiovascular events in patients with previous myocardial infarction [46]. Finally, red yeast rice in combination with low-dose statins, has been proved very effective in reducing LDL-C in patients with coronary artery disease, who were intolerant to statins, representing therefore a viable therapeutic alternative [47].

Berberine: Berberine is a plant product extracted from cortex of Berberis aristata. It can upregulate LDL receptors, thus leading to an increase in cholesterol reuptake with reduction in plasma values of total and LDL-C levels. Berberine also reduces the levels of triglycerides by inactivating acetyl coenzyme-A carboxylase that is involved in triglyceride synthesis [48].

Folic acid: Folic acid, or vitamin B 9, plays a critical role in converting homocysteine to methionine. A folic acid deficiency causes hyper-homocysteinemia, which is associated with a higher risk of CVD [49]. Several clinical studies have also demonstrated that folic acid improves endothelial function independently from homocysteine levels in the blood [50].
Flavonoids: Flavonoids are bioactive polyphenols and include a wide range of substances such as flavonols (present in onions, broccoli, tea), flavones (found in parsley, celery, chamomile), flavanols particularly catechins and procyanidins (present in cocoa, apples, grapes, red wine and tea), antrocianidine (found in red fruits) and isoflavones (present in soy). Flavonoids can lower blood pressure and have antioxidant, anti-platelet and anti-inflammatory effects [51]. Flavonoids are also reccomended for the treatment of chronic venous insufficiency, venous ulcers and hemorrhoids. Oral administration of $900 \mathrm{mg} /$ day of diosmin has indeed demonstrated to improve venous tone and lymphatic drainage, to reduce capillary permeability, and to protect the microcirculation from inflammatory processes [51].

Unlike other flavonoids, isoflavones (daidzein, genistein, glycitein) are colorless and almost exclusively found in leguminous plants with higher concentrations in soybeans. They are defined "Phyto-oestrogens" because they are structurally and functionally similar to human estrogen, although they possess only a weak estrogenic activity (approximately 1.000-10.000 times less than estradiol). A daily dose of $35-150 \mathrm{mg} /$ day can help women to relieve side effects of menopause (eg, hot flashes) and confers a protection against osteoporosis, breast cancer and cardiovascular diseases [52].

\section{Tea}

Tea is the most widely consumed beverage in the world, second only to water, and is present in three main varieties: green, black and oolong. Green tea has the highest polyphenol content while black tea has roughly 2 to 3 times the caffeine content of green tea.

Tea and Heart Attacks: Daily tea consumption has showed to lower the risk of coronary heart disease and stroke by $10 \%$ to $20 \%$ [53], probably due to beneficial effect of antioxidants on atherosclerosis and plaque buildup (Figure 3). A large study including data on more than 37000 individuals followed for 13 years, confirmed beneficial effect of tea against CVD [54].

Tea and Endothelial Function: Results from recent scientific studies suggest that black tea may reduce the risk of heart disease by maintaining healthy function of the endothelium [55]

Tea and Hypertension: Various studies proved that regular 


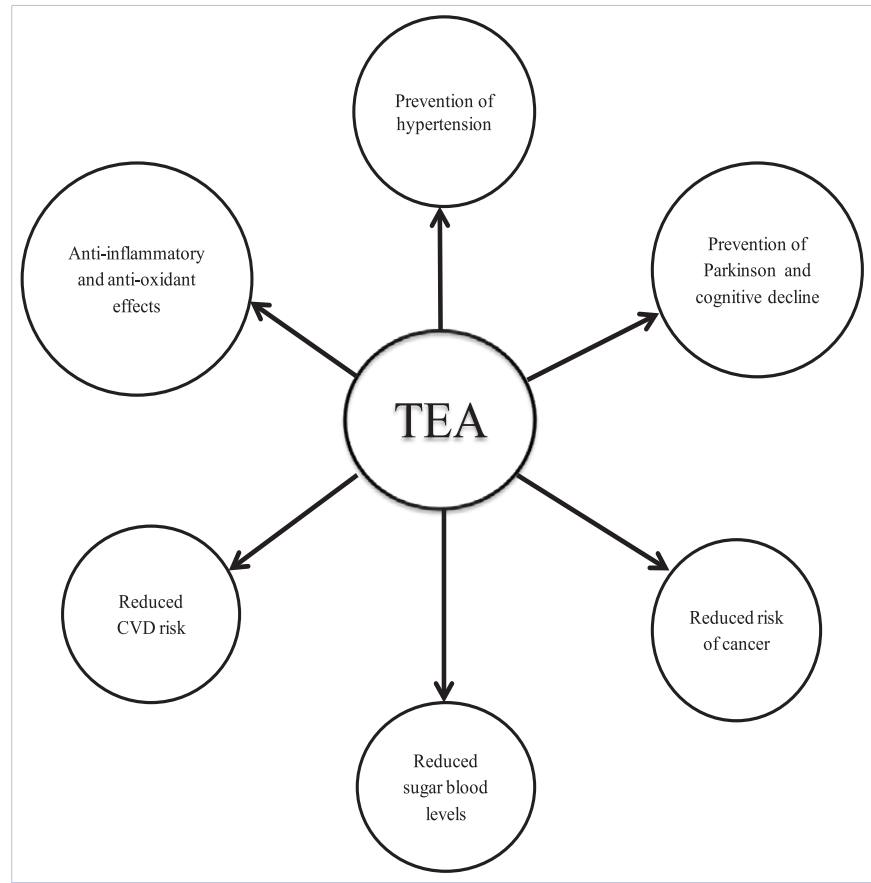

Figure 3: Tea: cardiovascular effects.

tea consumption might prevent hypertension, probably by counteracting the effects of Angiotensin II [56]. A recent study reported that consumption of black tea at a dose of three cups per day for six months, lowered both systolic and diastolic blood pressure [57]

Tea and Cholesterol: Green tea proved to reduce the risk of heart disease by lowering TC, LDL-C and triglyceride levels [58]. Moreover, high concentrations of autoantibodies against oxidized low-density lipoproteins have been found in patients with atherosclerosis [59].

Tea and diabetes: Finally, flavonoids in green tea have been proved to exert antidiabetic and insulin-like effects and to help prevent the development and progression of type 1 diabetes [60].

\section{Coffee}

The consumption of coffee has generally been regarded as being detrimental to heart health due to an eventual increase in blood pressure and risk of heart attack and cardiac arrhythmias. However, recent studies have suggested that coffee might not increase the risk of heart disease, and in fact might actually reduce it. Indeed, both caffeinated and decaffeinated coffees contain chlorogenic acid and trigonelline that exert anti-inflammatory actions [61]. They have been shown, for example, to reduce levels of the inflammatory cytokines IL-18 and 8-isoprostane, and to increase adiponectin, with consequent protective effect [61] (Figure 4).

Coffee and Blood Pressure: The effect of coffee on blood pressure appears to be mixed and is not exclusively dependent on caffeine. Prospective studies suggested a protective effect of coffee intake ( $\geq 4$ or cups/day) against hypertension, whilst randomized controlled trials, mostly of short duration (1-12 weeks), showed that coffee intake around 5 cups per day causes a small increase in blood pressure (1-2 mmHg)[62]. Overall, the evidence suggests that regular intake of caffeinated coffee does not increase the risk of hypertension, whilst in non-coffee drinkers, acute exposure to caffeine can increase the blood pressure by up to $10 \mathrm{~mm} \mathrm{Hg} \mathrm{[62].}$

Coffee and Diabetes: There is strong evidence that moderate coffee consumption lowers the risk of developing diabetes. Indeed, subjects with type II diabetes who drink $\geq 5$ cups of coffee per day were proved $30 \%$ less likely to die from CVD [63]. The same effect was observed with decaffeinated coffee, suggesting that this protective effect may not be related to caffeine [64]

Coffee and Cholesterol: Cafestol and kahweol, that are naturally present in coffee oil (but not in coffee brewed with paper filters), can increase the serum levels of total and LDL-C [65]. Various studies indeed, proved that coffee, both with or without caffeine, in particular when boiled or processed at high temperatures, is linked to higher levels of serum cholesterol [66].

Coffee and Coronary Artery Disease: A meta-analysis of 21 prospective cohort studies on coffee consumption and coronary heart disease failed to prove a statistically significant association between coffee drinking and the long-term risk of coronary heart disease [67]. Moreover, a Japanese study had observed statistically significant inverse associations between coffee consumption and mortality from CVD in women [68].

Coffee and Heart Failure: A recent meta-analysis suggests that moderate ( 1 to 4 cups/day) but not high ( $\geq 5$ cups/day) consumption of coffee, reduces the risk of developing heart failure [69]

Coffee and Arrhythmias: Although coffee increases heart rate, neither laboratory studies nor large population studies have demonstrated that moderate amounts of coffee increase the risk of cardiac arrhythmias, included AF [70]. Of note, a recent study suggested that drinking 4 cups of coffee per day reduces the

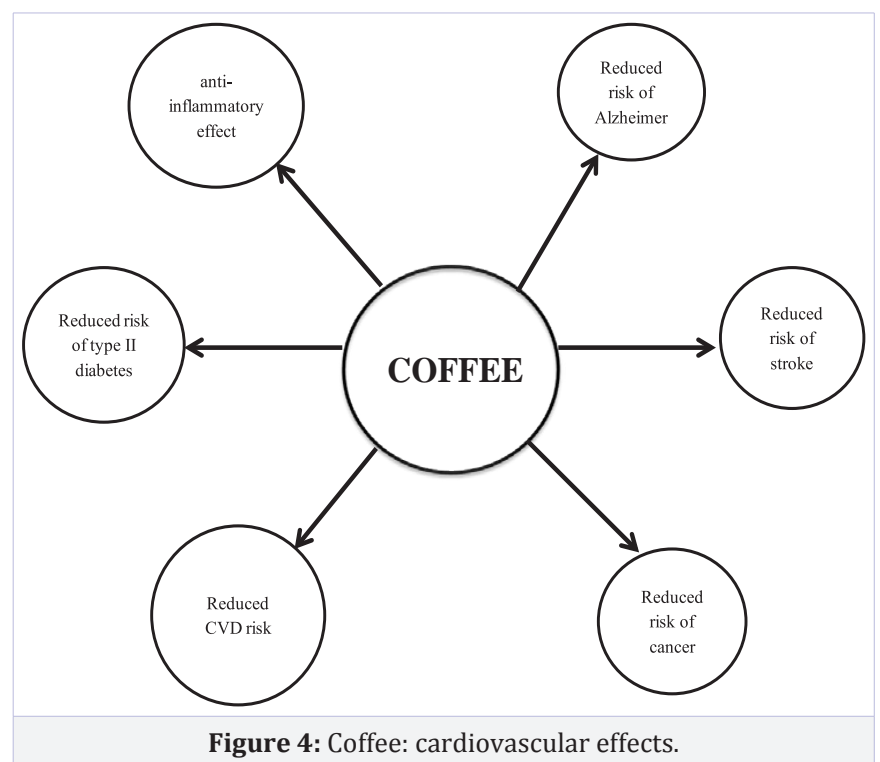


incidence of cardiac arrhythmias, including AF and ventricular premature contractions [71].

Coffee and Stroke: Various studies have shown that coffee consumption is associated with reduced risk of both ischemic and hemorrhagic stroke [72-73], probably due to beneficial effects on endothelial function. Other studies failed to prove any association between coffee consumption and the risk of stroke [74].

\section{Discussion}

Despite relatively recent declines in age-adjusted mortality, CVD is still the primary cause of death in developed countries [1]. The most preventable form of CVD is coronary heart disease that is favored by several risk factors including hypertension, dislipidemia, diabetes and obesity. Several studies have proved that a healthy lifestyle is the cornerstone of primary prevention and may lead to better results than any drug therapy. The importance, in particular, of an equilibrate diet, rich in vegetables, cereals and fruit, and poor in red meat and sweets, is well known. The Mediterranean diet indeed, has proved to be protective against atherogenesis, cholesterol and diabetes [9-10], and has demonstrated to reduce mortality from coronary diseases and stroke [11].

Antioxidant agents, including Vitamin E and beta-carotene, have proved to counteract reactive oxigen species, thus preventing vascular dysfunction. However, contrarily to popular belief, vitamin supplements have demonstrated to be a weak substitute for a balanced, nutritious diet. Indeed neither vitamin E nor beta-carotene supplementations alone have proved to reduce mortality or CVD [17-18].

Conversely, nutraceutical agents, including N-3 PUFA, polyphenols, red yeast rice, berberine, folic acid and flavonoids, have proved to be useful for prevention of CVD [20-52]. N-3 PUFA in particular, by reducing LDL-C and triglycerides, have proved to prevent ischemic heart disease [22]. Moreover, due to multiple direct and indirect effect, they have showed beneficial effects in term of prevention of AF [27-41] and of sudden cardiac death soon after a myocardial infarction [23-26].

Phytosterols and berberine have proved to reduce LDL-C while resveratrol has demonstrated to inhibit LDL oxidation and to suppress platelet aggregation $[43,48]$. Monacolin $\mathrm{K}$ has showed to reduce LDL cholesterol and to be useful for primary and secondary prevention of ischemic cardiac disease [45-47]. Finally, folic acid has demonstrated to improve endothelial function, while flavonoids have proved to lower blood pressure and to exert an antioxidant, anti-platelet and anti-inflammatory effects [49-52].

Daily tea consumption has demonstrated to reduce the risk of coronary heart disease and stroke, to help prevent hypertension and to lower cholesterol and triglyceride levels [53-60]. Finally, although coffee has been considered dangerous for CVD for a long time, several studies failed to prove an association between coffee and risk of coronary heart disease, as well as of ventricular arrhythmias, and regular moderate coffee intake has proved not to increase the risk of hypertension.

In summary, a well balanced diet including a moderate daily consumption of green tea or coffee, eventually enriched with nutraceuticals, has proved to reduce risk factor and the incidence of CVD.

\section{Conclusion}

A healthy diet, rich in vegetables, cereals and fruits and poor in red meat and sweets, is the cornerstone of CVD prevention and may not be safely substituted by isolated vitamin intake. Nutraceuticals can be of help for reducing cholesterol and triglycerides. Tea and Coffee, when consumed regularly, at a moderate dosage, may also be useful for CVD prevention.

\section{References}

1. Lozano R, Naghavi M, ForemanK, Lim S, Shibuya K ,Victor Aboyans, et al. Global and regional mortality from 235 causes of death for 20 age groups in 1990 and 2010: a systematic analysis for the Global Burden of Disease Study 2010. Lancet. 2012;380(9859):2095-2128. doi:10.1016/S0140-6736(12)61728-0

2. Jørgensen T, Capewell S, Prescott E, Allender S, Sans S, Zdrojewski T, et al. Population-level changes to promote cardiovascular health. Eur J Prev Cardiol. 2013;20(3):409-421. doi:10.1177/2047487312441726

3. Perk J, De Backer G, Gohlke H, Graham G, Reiner Z, Monique Verschuren, et al. European guidelines on cardiovascular disease prevention in clinical practice. Eur Heart J. 2012;33:1635-1701. doi:10.1093/ eurheartj/ehs092.

4. Capewell S and O'Flaherty M. Rapid mortality falls after riskfactor changes in populations. Lancet. 2011;378(9793):752-753. doi:10.1016/S0140-6736(10)62302-1.

5. Sacks FM, Pfeffer MA, Moye LA, Rouleau JL, Rutherford JD, Thomas GC, et al. The effect of pravastatin on coronary events after myocardial infarction in patients with average cholesterollevels. N Engl J Med. 1996;335:1001-1009. DOI:10.1056/NEJM199610033351401.

6. Baigent C, Blackwell L, Emberson J, Holland LE, Reith C, Bhala N, et al. Cholesterol Treatment Trialists (CTT) Collaboration. Efficacy and safety of more intensive lowering of LDL cholesterol: a meta-analysis of data from 170000 participants in 26 randomised trials. Lancet. 2010;376(9753):1670-1681. doi:10.1016/S0140-6736(10)61350-5.

7. Cuchel M, Bruckert E, Ginsberg HN, Raal FJ, Santos RD, Hegele RA, et al. Homozygous familial hypercholesterolaemia: new insights and guidance for clinicians to improve detection and clinical management. A position paper from the Consensus Panel on Familial Hypercholesterolaemia of the European Atherosclerosis Society Eur Heart J. 2014;35(32):2146-2157. doi:10.1093/eurheartj/ehu274

8. Traynor K. Evolocumab approved for reducing LDL cholesterol. Am J Health Syst Pharm. 2015;72(19):1599-1600. doi:10.2146/ news150066.

9. Justin Y, Farioli A, Korre M, Kales SN. Modified Mediterranean Diet Score and Cardiovascular Risk in a North American Working Population. PLoS ONE. 2014;9:e87539. doi:10.1371/journal.pone.0087539

10. Miedema MD, Petrone A, Shikany JM, Greenland P, Lewis CE, Pletcher MJ, et al. Association of Fruit and Vegetable Consumption During Early Adulthood With the Prevalence of Coronary Artery Calcium 
After 20 Years of Follow-Up The Coronary Artery Risk Development in Young Adults (CARDIA) Study. Circulation. 2015;132(21):19901998. doi:10.1161/CIRCULATIONAHA.114.012562.

11. Fung TT, Rexrode KM, Mantzoros CS, Manson JE, Willett WC, Hu FB. Mediterranean diet and incidence and mortality of coronary heart disease and stroke in women. Circulation. 2009;119(12):1093-1100. doi:10.1161/CIRCULATIONAHA.108.816736.

12. Estruch R, Ros E, Salas-Salvadó J, Covas MI, Corella D, Fernando Arós, et al. Primary Prevention of Cardiovascular Disease with a Mediterranean Diet. N Engl J Med. 2013;368:1279-1290. DOI:10.1056/NEJMoa1200303

13. Appel LJ, Moore TJ, Obarzanek E, Vollmer WM, Svetkey LP, Sacks FM, et al. A clinical trial of effects of dietary patterns on blood pressure. DASH collaborative reserce groups. N Engl J Med. 1997;336:11171124. DOI:10.1056/NEJM199704173361601

14. Liese AD, Bortsov A, Günther AL, Dabelea D, Reynolds K, Standiford DA, et al. Association of DASH Diet With Cardiovascular Risk Factors in Youth With Diabetes Mellitus The SEARCH for Diabetes in Youth Study. Circulation. 2011;123:1410-1417. doi:10.1161/ CIRCULATIONAHA.110.955922.

15. Ross R. The pathogenesis of atherosclerosis: a perspective for the 1990s. Nature. 1993;362(6243):801- 809.

16. Diaz MN, Frei B, Vita JA, Keaney JF Jr. Antioxidants and atherosclerotic heart disease. N Engl J Med. 1997;337:408-416.

17. Vivekananthan DP, Penn MS, Sapp SK, Hsu A, Topol EJ. Use of antioxidant vitamins for the prevention of cardiovascular disease: meta-analysis of randomised trials. Lancet. 2003;361(9374):20172023.

18. Moyer VA, LeFevre ML, Sin AL, Baumann LC, Curry SJ, Ebell M, et al Vitamin Mineral, and Multivitamin Supplements for the Primary Prevention of Cardiovascular Disease and Cancer: U.S. Preventive Services Task Force Recommendation Statement. Ann Intern Med. 2014;160(8):558-564. doi:10.7326/M14-0198.

19. Huaidong Du, Liming L, Bennett D, Gou Y, Key T, Zheng B, et al. Fresh Fruit Consumption and Major Cardiovascular Disease in China. N Engl J Med. 2016;374:1332-1343. DOI:10.1056/NEJMoa1501451

20. Robert EC Wildman. Handbook of Nutraceuticals and Functional Foods, (1st Ed), CRC Series in Modern Nutrition. 2001

21. Harris WS, Mozaffarian D, Rimm E, Kris-Etherton P, Rudell LL, Lawerence JA, et al. Omega-6 fatty acid and risk for cardiovascular disease: a science advisory from the American Heart Association Nutrition Subcommittee of the Council on Nutrition, Physical Activity and Metabolism, Council on Cardiovascular Nursing and Council on Epidemiology and Prevention. Circulation. 2009;119:902-907. doi: 10.1161/CIRCULATIONAHA.108.191627

22. Calò L, Martino A, Tota C. The anti-arrhythmic effects of n-3 PUFAs. Int J Cardiol. 2013;170(2 Suppl 1):S21-27. doi: 10.1016/j. ijcard.2013.06.043.

23. Dietary supplementation with $n-3$ polyunsaturated fatty acids and vitamin $\mathrm{E}$ after myocardial infarction: results of the GISSIPrevenzione trial. Lancet. 1999;354:447-455. DOI: http://dx.doi. org/10.1016/S0140-6736(99)07072-5.

24. Yokoyama M, Origasa H, Matsuzaki M, Matsuzawa Y, Saito Y, Yuichi Ishikawa, et al. Effects of eicosapentaenoic acid on major coronary events in hypercholesterolaemic patients (JELIS): a randomised open-label, blinded endpoint analysis. Lancet. 2007;369(9567):10901098. doi: 10.1016/S0140-6736(07)60527-3.
25. Rauch B, Schiele R, Schneider S, Diller F, Victor N, Gohlke H, et al. OMEGA, a randomized, placebo-controlled trialto test the effect of highly purified omega-3 fatty acids on top of modern guidelineadjusted therapy after myocardial infarction. Circulation. 2010;122:2152-2159. doi: 10.1161/CIRCULATIONAHA.110.948562.

26. Kromhout D, Giltay EJ, Geleijnse JM. N-3 fatty acids and cardiovascular events after myocardial infarction. N Engl Med. 2010;363:20152026. DOI: 10.1056/NEJMoa1003603.

27. Mozaffarian D, Psaty BM, Rimm EB, Lemaitre RN, Burke GL, Mary F. Lyles, etal. Fish intake and risk of incidentatrial fibrillation. Circulation. 2004;110:368-373. doi: 10.1161/01.CIR.0000138154.00779.A5

28. Wu JH, Lemaitre RN, King IB, Song X, Sacks FM, Rimm EB, et al. Association of Plasma Phospholipid Long-Chain Omega-3 Fatty Acids With Incident Atrial Fibrillation in Older Adults: The Cardiovascular Health Study. Circulation. 2012;125(9):1084-1093. doi: 10.1161/ CIRCULATIONAHA.111.062653.

29. Frost L, Vestergaard P. N-3 fatty acids consumed from fish and risk of atrial fibrillation or flutter: the Danish Diet, Cancer, and Health study. Am J Clin Nutr. 2005;81(5):50-54.

30. Brouwer IA, Heeringa J, Geleijnse JM, Zock PL, Witteman JC. Intake of very long-chain $\mathrm{n}-3$ fatty acids from fish and incidence of atrial fibrillation. The Rotterdam study. Am Heart J. 2006;151(4):857-862.

31. Virtanen JK, Mursu J, Voutilainen S, Tuomainen TP. Serum long-chain n-3 polyunsaturated fatty acids and risk of hospital diagnosis of atrial fibrillation in men. Circulation. 2009;120(23):2315-2321. doi: 10.1161/CIRCULATIONAHA.109.852657.

32. Cleland GJF, Coletta AP, Castiello T, Clark AL. Clinical trials update from the European Society of Cardiology Heart Failure meeting 2011: TEHAF, WHICH, CARVIVA, and atrial fibrillation in GISSI-HF and EMPHASIS-HF. Eur J Heart Fail. 2011;13(10):1147-1151. doi: 10.1093/eurjhf/hfr119.

33. Nodari S, Triggiani M, Campia U, Manerba A, Milesi G, et al. N-3 polyunsaturated fatty acids in the prevention of atrial fibrillation recurrences after electrical cardioversion: a prospective, randomized study. Circulation. 2011;124:1100-1106. doi: 10.1161/ CIRCULATIONAHA.111.022194.

34. Kumar S, Sutherland F, Morton JB, Lee G, Morgan J, Wong J, et al. Long-term omega-3 polyunsaturated fatty acid supplementation reduces the recurrence of persistent atrial fibrillation after electrical cardioversion. Heart Rhythm. 2012;9(4):483-491. doi: 10.1016/j. hrthm.2011.11.034.

35. Macchia A, Grancelli H, Varini S, Nul D, Laffaye N, et al. Omega-3 fatty acids for the prevention of recurrent symptomatic atrial fibrillation: results of a double-blind randomized clinical trial (FORWARD). J Am Coll Cardiol. 2013;61(4):463-468. doi: 10.1016/j.jacc.2012.11.021.

36. Nigam A, Talajic M, Roy D, Nattel S, Lambert J, Anna Nozza, et al. Fish oil for the reduction of atrial fibrillation recurrence, inflammation and oxidative stress. J Am Coll Cardiol. 2014;64(14):1441-1448. doi:10.1016/j.jacc.2014.07.956.

37. Darghosian L, Free M, Li J, Gebretsadik T, Bian A, Shintani A, et al. Effect of omega three polyunsaturated fatty acids on inflammation, oxidative stress and recurrence of atrial fibrillation. Am J Cardiol. 2015;115(2):196-201. doi: 10.1016/j.amjcard.2014.10.022.

38. Calò L, Bianconi L, Colivicchi F, Lamberti F, Loricchio ML, de Ruvo E, et al. N-3 fatty acids for the prevention of atrial fibrillation after coronary artery bypass surgery. A randomized, controlled trial. J Am Coll Cardiol. 2005;45(10):1723-1728. 
39. Sandesara CM, Chung MK, Van Wagoner DR, Barringer TA, Allen $\mathrm{K}$, et al. A Randomized, Placebo-Controlled Trial of Omega-3 Fatty Acids for Inhibition of Supraventricular Arrhythmias After Cardiac Surgery: The FISH Trial. J Am Heart Assoc:e000547.

40. Saravanan P, Bridgewater B, West AL, O'Neill SC, Calder PC, Davidson NC. Omega-3 fatty acid supplementation does not reduce risk of atrial fibrillation following coronary artery bypass surgery: a randomized, double blind, placebo controlled clinical trial. Circ Arrhythm Electrophysiol. 2010;3(1):46-53. doi: 10.1161/CIRCEP.109.899633.

41. Mozaffarian D, Marchioli R, Macchia A, Silletta MG, Ferrazzi P, Gardner T], et al. OPERA Investigators. Fish Oil and Postoperative Atrial Fibrillation The Omega-3 Fatty Acids for Prevention of Postoperative Atrial Fibrillation (OPERA) Randomized Trial. JAMA 2012;308(19):2001-2011.

42. Martino A, Pezzi L, Magnano R, Salustri E, Penco M and L Calò Omega 3 and atrial fibrillation: Where are we? World J Cardiol. 2016;8(2):114-119. doi: 10.4330/wjc.v8.i2.114

43. Castañer O, Covas MI, Khymenets O, Nyyssonen K, Konstantinidou $\mathrm{V}$, Zunft HF, et al. Protection of LDL from oxidation by olive oil polyphenols is associated with a downregulation of CD40-ligand expression and its downstream products in vivo in humans. Am J Clin Nutr. 2012;95(3):1238-1244. doi: 10.3945/ajcn.111.029207

44. Mukherjee S, J Dudley, and D Das. Dose-dependency of Resveratrol in providing health benefits. Dose Response. 2010;8(4):478-500. doi: 10.2203/dose-response.09-015

45. Li Y, Jiang L, Jia Z, Wei Xin, Shivei Yahng, Yang Q, et al. A meta-analysis of red yeast rice: an effective and relatively safe alternative approach for dyslipidemia. PLoS One. 2014;9(6):e98611.

46. Lu Z, Kou W, Du B, Wu Y, Zhao S, Brusco OA, et al. Effect of Xuezhikang an extract from red yeast Chinese rice, on coronary events in a Chinese population with previous myocardial infarction. Am J Cardiol. 2008;101:1689-1693. doi: 10.1016/j.amjcard.2008.02.056

47. Marazzi G, Pelliccia F, Quattrino S, Cacciotti L, Volterrani M Campolongo G, et al. Usefulness of Nutraceuticals (Armolipid Plus) Versus Ezetimibe and Combination in Statin-Intolerant Patients With Dyslipidemia With Coronary Heart Disease. Am J Cardiol. 2015;116(12):1798-1801. doi: 10.1016/j.amjcard.2015.09.023

48. Cicero AF, Rovati LC, Setnikar I. Eulipidemic effects of berberine administered alone or in combination with other natural cholesterol-lowering agents. A single-blind clinical investigation. Arzneimittelforschung. 2007;57(1):26-30.

49. Moat SJ, Lang D, McDowell IF, Clarke ZL, Madhavan AK, et al. Homocysteine, endothelial function and cardiovascular disease. J Nutr Biochem. 2004;15:64-79.

50. Moens AL, Claeys MJ, Wuyts FL, Goovaerts I, Van Hertbruggen E, Wendelen LC, et al. Effect of folic acid on endothelial function following acute myocardial infarction. Am J Cardiol. 2007;99(4):476481.

51. Taubert D, Roesen R, Lehmann C, Jung N, Schömig E. Effects of low habitual cocoa intake on blood pressure and bioactive nitric oxide: a randomized controlled trial. JAMA. 2007;298(1):49-60.

52.Munro IC, Harwood M, Hlywka JJ, Stephen A, Doull JJ, Flamm WG, et al. Soy isoflavones: a safety review. Nutr Rev. 2003;61(1):1-33.

53. Bøhn SK, Ward NC, Hodgson JM, Croft KD. Effects of tea and coffee on cardiovascular disease risk. Food Funct. 2012;3(6):575-591. doi: $10.1039 /$ c2fo10288a.
54. De Koning Gans JM, Uiterwaal CS, van der Schouw YT, Grobbee $\mathrm{DE}$, Verschuren $\mathrm{WM}$, et al. Tea and coffee consumption and cardiovascular morbidity and mortality. Arterioscler Thromb Vasc Bio. 2010;30(8):1665-1671. doi: 10.1161/ATVBAHA.109.201939.

55. Duffy SJ, JF Keaney Jr, Holbrook M, Gokce N, Swedloff P, Frei B, et al. Short-and long-term black tea consumption reverses endothelial dysfunction in patients with coronary artery disease. Circulation. 2001;104(2):151-156

56. Antonello M, Montemurro D, Bolognesi M, Di Pascoli M, Piva A, Grego $\mathrm{F}$, et al. Prevention of Hypertension, Cardiovascular Damage and Endothelial Dysfunction with Green Tea Extracts. Am J Hypertension. 2007;20(12):1321-1328.

57. Hodgson JM, Puddey IB, Woodman RJ, Mulder TP, Fuchs D, Scott K, et al. Effects of black tea on blood pressure: a randomized controlled trial. Arch Intern Med. 2012;172(2):186-188. doi: 10.1001/ archinte.172.2.186.

58. Kim A, Chiu A, Barone MK, Avino D, Wang F, Coleman CI et al. Green tea catechins decrease total and low-density lipoprotein cholesterol: a systematic review and meta-analysis. J Am Diet Assoc. 2011;111(11):1720-1729. doi: 10.1016/j.jada.2011.08.009.

59. Salonen JT, Yla-Herttuala S, Yamamoto R, Butler S, Korpela H, Salonen R, et al. Autoantibody against oxidised LDL and progression of carotid atherosclerosis. Lancet. 1992;339(8798):883-887.

60. Wu LY, Juan CC, Ho LT, Hsu YP, Hwang LS. Effect of green tea supplementation on insulin sensitivity in Sprague-Dawley rats. J Agric Food Chem. 2004;52(3):643-648.

61. Wedick NM, Brennan AM, Sun Q, Hu FB, Mantzoros CS, van Dam RM. Effects of caffeinated and decaffeinated coffee on biological risk factors for type 2 diabetes: a randomized controlled trial. Nutr J. 2011;10:93. doi: 10.1186/1475-2891-10-93.

62. Geleijnse JM. Habitual coffee consumption and blood pressure: An epidemiological perspective. Vasc Health Risk Man. 2008;4(5):963970.

63. Muley A, Muley P, Shah M. Coffee to reduce risk of type 2 diabetes?: a systematic review. Curr Diabetes Rev. 2012;8(3):162-168.

64. Bidel S, Hu G, Qiao Q, Jousilahti P, Antikainen R, Tuomilehto J. Coffee consumption and risk of total and cardiovascular mortality among patients with type 2 diabetes. Diabetologia. 2006;49(11):2618-2626.

65. Urgert R and Katan MB. The cholesterol-raising factor from coffee beans. J R Med. 1996;89(11):618-623.

66. Lindahl B, Johansson I, Huhtasaari F, Hallmans G and Asplund K. Coffee drinking and blood cholesterol--effects of brewing method, food intake and life style. Journal of Internal Medicine. 1991;230(4):299305.

67. Wu J, Ho SC, Zhou C, Ling WH, Chen WQ, Wang CL, et al. Coffee consumption and the risk of coronary heart disease: a meta-analysis of 21 prospective cohort studies. Int J Cardiol. 2009;137(3):216-225. doi: 10.1016/j.ijcard.2008.06.051

68. Sugiyama K, Kuriyama S, Akhter M, Kakizaki M, Nakaya N, OhmoriMatsuda K, et al. Coffee consumption and mortality due to all causes, cardiovascular disease, and cancer in Japanese women. J Nutr. 2010;140(5):1007-1013. doi: 10.3945/jn.109.109314

69. Mostofsky E, Rice MS, Levitan EB, Mittleman MA. Habitual coffee consumption and risk of heart failure: a dose-response metaanalysis. Circ Heart Fail. 2012;5(4):401-405. doi: 10.1161/ CIRCHEARTFAILURE.112.967299 
70. Conen D, S Chiuve, B Everett, S Zhang, J Buring, Albert CM. Caffeine consumption and incident atrial fibrillation in women. Am J Clin Nutr. 2010;92(3):509-514. doi: 10.3945/ajcn.2010.29627

71. Klatsky AL, Hasan AS, Armstrong MA, Udaltsova N, Morton C. Coffee, caffeine, and risk of hospitalization for arrhythmias. Perm J. 2011;15(3):19-25

72. Thrift AG, McNeil JJ, Forbes A, Donnan GA. Risk factors for cerebral hemorrhage in the era of well-controlled hypertension. Melbourne Risk Factor Study (MERFS) Group. Stroke. 1996;27(11):2020-2025.
73. Lopez-Garcia E, Rodriguez-Artalejo F, Rexrode KM, Logroscino G, Hu FB, Van Dam RM. Coffee consumption and risk of stroke in women. Circulation. 2009;119(8):1116-1123. doi: 10.1161/ CIRCULATIONAHA.108.826164.

74. Leurs LJ, Schonten LJ, Goldbohm RA, Van den Brandt PA. Total fluid and specific beverage intake and mortality due to ID and stroke in the Netherlands cohort study. Br J Nutr. 2010;104(8):1212-1221. doi: $10.1017 /$ S0007114510001923. 